\section{HISTÓRIA DA OBESIDADE NO CINEMA: A LUTA DOS SEXOS (1928) de D. W. GRIFFITH}

HISTORY OF OBESITY IN CINEMA: THE BATTLE OF THE SEXES (1928) BYD.W. GRIFFITH C

HISTORIA DE LA OBESIDAD EN EL CINE: LA LUCHA DE LOS SEXOS (1928) de D. W. GRIFFITH C

doi' https://doi.org/10.22456/1982-8918.114205

(iD) Cezar Barbosa Santolin* <cezarsantolin@hotmail.com>

(iD Luiz Carlos Rigo** <rigoperini@gmail.com>

*Universidade Federal do Mato Grosso do Sul (UFMS). Corumbá, MS, Brasil.

${ }^{* *}$ Universidade Federal de Pelotas (UFPel). Pelotas, RS, Brasil.

Resumo: O objetivo deste artigo foi analisar Aluta dos sexos (1928), de D. W. Griffith, como uma fonte primária da história da obesidade no cinema. Metodologicamente, utilizou-se análise discursiva da enunciação numa perspectiva foucaultiana. As análises permitiram constatar a importância que a questão da obesidade e da circunferência abdominal assumem na trama. Ambas são tornadas simbólicas e os novos valores, retratados negativamente, como uma ameaça, indireta, à integridade das famílias. Consequentemente, a barriguinha e a pouca importância dada pela esposa e pelos filhos devido ao amor verdadeiro que sentem pelo marido/pai se tornam símbolos de boa paternidade, de fidelidade e da integridade familiar. Concluise que o filme é uma peça importante na história da obesidade tanto porque Griffith foi um dos cineastas mais importantes da história do cinema e esse um dos seus filmes mais famosos quanto pela raridade da formação discursiva.

Palavras chave: Obesidade. História. Filmes cinematográficos.
Recebido em: 24 mai. 2021 Aprovado em: 27 dez. 2021 Publicado em: 09 fev. 2022

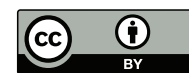

Este é um artigo publicado sob a licença Creative Commons Atribuição 4.0 Internacional (CC BY 4.0). 


\section{INTRODUÇÃO}

Em meados do século XVIII, encontram-se os primeiros discursos patologizantes ${ }^{1}$ da condição atualmente denominada obesidade, definida como excesso de gordura corporal, especificada através do Índice de Massa Corporal (IMC). Essas formulações discursivas que desencadearam também uma inversão valorativa daquilo que era denominado corpulência foram engendradas, principalmente, na França e na Inglaterra. A condição - até então valorizada como bela, rica e salutar - começa a ser alvo de problematizações de diferentes modos, como no âmbito estético, moral, da saúde, socioeconômico e, até mesmo, político-ideológico. Por cerca de um século, os discursos de inversão valorativa vão florescer em campos específicos, como na medicina, mas sem quaisquer fundamentos científicos, com um discurso patologizante, sem, porém, realmente se popularizar, o que só ocorrerá ao longo do século XX (SANTOLIN; RIGO, 2012, 2015).

Ainda que tais fatos já sejam conhecidos, não se sabe como ocorreu a popularização de uma inversão sociocultural de valores milenares relacionados à corpulência. Além de acontecimentos reais, tais como a urbanização, cogita-se que um acontecimento sociocultural de tamanha envergadura demande também uma ferramenta de comunicação em massa de convencimento poderosa.

Neste sentido, assumiu-se a hipótese de que o cinema, inventado no final do século XIX, pode ter sido um instrumento para a divulgação dos novos valores relativos à obesidade e seus precursores conceituais ${ }^{2}$. Assim, compondo uma história serial maior (BARROS, 2011, 2012, 2013), o presente artigo buscou analisar um dos filmes mais famosos do renomado diretor D. W. Griffith - The battle of the sexes (A luta dos sexos, 1928).

David Wark Griffith - mais conhecido pelo acrônimo D. W. Griffith (Figura 1) - nasceu no Kentucky, Estados Unidos da América, em 1875. Antes de tornar-se cineasta atuou em diversas ocupações, como mineiro, vendedor de enciclopédias e operário de uma serraria - para citar algumas. No cinema, Griffith é considerado um dos mais importantes diretores da história, tendo dirigido cerca de 450 curtasmetragens, além de vários longas-metragens (SABADIN, 2000).

\footnotetext{
1 Foucault (2001) denominou de "medicalização do discurso" o que aqui é tratado como "discurso patologizante". Esta mudança terminológica foi feita também por considerar que tais práticas discursivas não se restringem aos médicos, como poderia ser deduzido a partir da palavra "medicalização". Além das características apresentadas pelo pensador francês - sintomatologia, nosografia, classificação e taxionomia -, acrescentam-se à noção de "discurso patologizante": 1) a enunciação, por parte de agentes específicos, segundo a qual os sujeitos portadores de determinadas características são "doentes"; e 2) a prescrição ou imposição de um "tratamento" - que é o momentoexercício efetivo do saber-poder, entendido como submissão, voluntária ou não, do doente ao terapeuta ou a um certo complexo industrial terapêutico, a fim de normalizá-lo. As práticas que se outorgam ou almejam o estatuto de "terapêuticas" necessitam de um "discurso patologizante" que as fundamentem e legitimem para o estabelecimento de uma relação de saber-poder deste tipo (SANTOLIN, RIGO, 2015).

2 Mais sobre etimologia e precursores conceituais podem ser encontrados em Santolin e Rigo (2012a).
} 
Figura 1 - D. W. Griffith

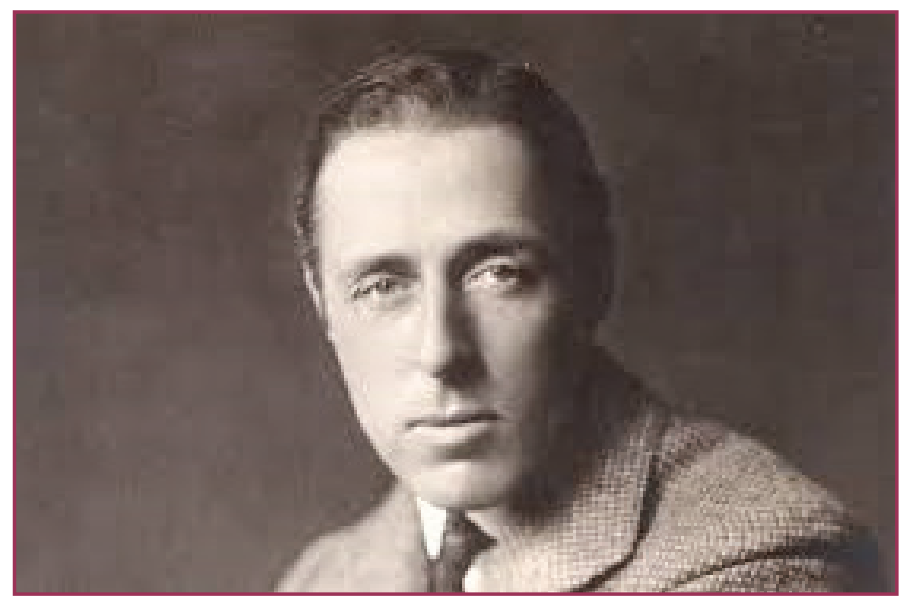

Fonte: IMDb, 2018

A importância de Griffith para a cinematografia é tanta que alguns historiadores do cinema, como Cousins (2013), chegam a se referir a uma era pré ou pós-griffithiana. Como destacado por Sabadin (2000, p.86)

Sua produção já se mostra rica no domínio da linguagem cinematográfica, com mudanças nos ângulos das câmeras, ações paralelas, iluminação dramática, bom ritmo de edição, closes e outros recursos que - se não foram exatamente inventados por Griffith - nele encontraram um grande realizador. Além disso, ele ensaiava seus atores de maneira diferenciada, tentando extrair deles interpretações menos teatrais que as utilizadas até então, sempre buscando maior naturalidade e espontaneidade das ações.

Chaplin (2015, p. 211) - renomado ator e diretor - escreveu em sua autobiografia sobre Griffith: "Era, inegavelmente, o gênio do cinema mudo".

Dentre as obras mais conhecidas de Griffith podem-se citar Intolerância (1916) e O nascimento de uma nação (1915). Esta figura entre as maiores bilheterias do ano de sua produção (WORLDWIDEBOXOFFICE, 2022). Não foram encontradas informações a respeito da bilheteria do filme A luta dos sexos (1928).

Os filmes do cineasta são comumente categorizados nos gêneros cinematográficos drama, romance e/ou histórico. Este perfil destoa um pouco da produção típica do cinema mudo, caracterizada mais por comédias, conforme ressalta Sabadin (2000, p.129):

É certo que - à exceção do musical - todos os gêneros cinematográficos nasceram já na época do cinema sem palavras. Porém, nenhum foi tão associado aos filmes mudos como a comédia. É como se a comédia muda fosse a própria essência das primeiras décadas do cinema. Uma perfeita interação de imagens, movimentos e situações impossíveis que arrancavam gargalhadas das plateias. Foram dezenas os cômicos e clowns que surgiram, fizeram sucesso, enriqueceram ou não, e desapareceram durante os anos do cinema mudo.

Além do famoso Charles Chaplin, outros nomes que fizeram muito sucesso na época foram Buster Keaton, Harold Lloyd, Mack Sennett e Max Linder (COUSINS, 2013; SABADIN, 2000). 
Figura 2 - Capa do filme A luta dos sexos (1928)

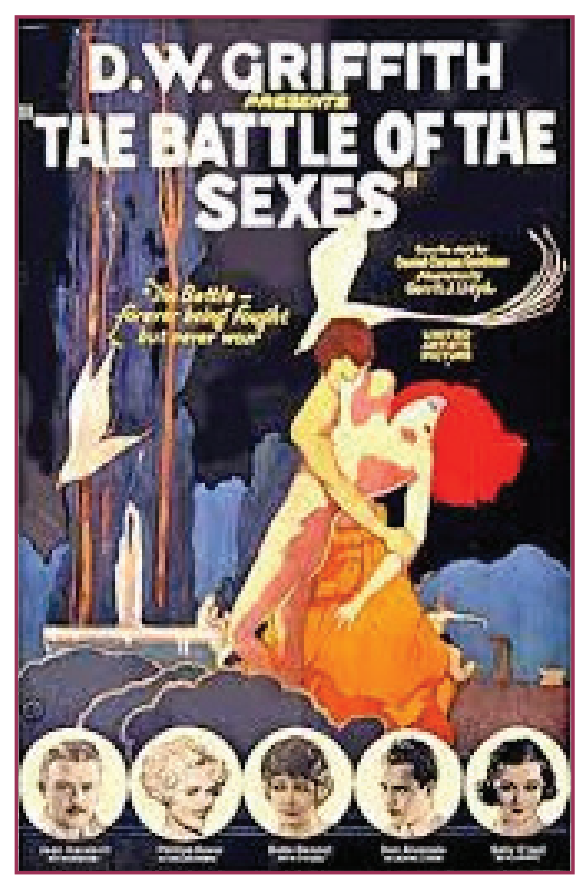

Fonte: IMDb, 2018

A prevalência de comédias torna interessante o recorte do cinema mudo para pesquisar as representações da obesidade e de seus precursores conceituais. A valorização e a desvalorização social tendem a coinstituir argumentos-satélites de convencimento dos benefícios e malefícios de tal aspecto, respectivamente. Esses argumentos, muitas vezes, podem lançar mão de estratégias de retórica, tal como a comicidade, para alcançar o efeito de convencimento desejado. Além disso, de acordo com Goffman (1980), o riso pode ser um dos instrumentos de estigmatização social e, portanto, tal como na atualidade, a comédia é um gênero cinematográfico privilegiado para a tematização - direta ou indireta - de condições desvalorizadas socioculturalmente, assim como para incitar transvalorações.

Isso não quer dizer que só havia comédias no cinema mudo. Além de Griffith, diretores como Sergei M. Eisenstein e F. W. Murnau se notabilizaram por filmes históricos e de terror, respectivamente (SABADIN, 2000; COUSINS, 2013).

Inversamente, o próprio Griffith não produziu somente dramas, romances e filmes históricos - também houve comédias, tal como The battle of the sexes (Figura2), lançada em 1928. O filme A luta dos sexos (1928) é um remake de filme homônimo, realizado em 1914, pelo mesmo diretor. O mais antigo, entretanto, aparentemente, não foi conservado. Tem-se, portanto, somente a película de 1928. Ambos são baseados na novela The single standard, de Daniel Carson Goodman, publicada em 1929.

\section{MATERIAIS E MÉTODOS}

As características deste ensaio permitem classificá-lo como uma pesquisa histórica e como um estudo de caso (STRUNA, 2007; THOMAS; NELSON; SILVERMAN, 2007; YIN, 2015). O filme-caso, constituído aqui enquanto fonte histórica 
primária (STRUNA, 2007), foi selecionado, arbitrariamente, por corresponder e se enquadrar na hipótese analítica de uma tese doutoral ${ }^{3}$ maior do tipo história serial (BARROS, 2011, 2012, 2013).

O filme The battle of the sexes, lançado em 1928, encontra-se em domínio público ${ }^{4}$ e pode ser acessado gratuitamente através da plataforma online de vídeos YouTube. Após o acesso, os dados foram analisados conforme a metodologia denominada análise discursiva da enunciação na perspectiva de Michel Foucault (2008). Essa opção deu-se por se tratar de uma análise interessada nos enunciados presentes nos discursos, na composição de formações discursivas.

Procedimentalmente, realizou-se uma primeira assistência, desenvolvendo uma análise geral da obra, identificando o tema do filme e possíveis trechos que poderiam ser considerados relevantes para a temática em questão. Feito isso, tendo considerado o material relevante, realizou-se uma segunda visualização, na qual foram descritas com maior grau de detalhamento as passagens selecionadas, recorrendo ao uso do período do filme em que ocorrem, devido à dificuldade de citação dos conteúdos dos filmes. Após isso, buscou-se constituir, a partir das descrições e análises, quais enunciados a respeito da obesidade, dos obesos e de seus precursores conceituais estariam presentes nas representações sociais (RS) do filme. Cada trecho foi categorizado em um ou mais núcleos centrais (NC) de significado, de acordo com o conteúdo de suas RS. Este procedimento advém da Teoria do Núcleo Central (TNC), de J. C. Abric e C. Flament (PATRIOTA, 2020), derivada da Teoria das Representações Sociais (TRS), de Serge Moscovici (2010).

Dada a possibilidade de contestação crítica às análises e interpretações, devido às características inerentes à atividade hermenêutica, mantiveram-se citações aos períodos do filme analisado, assim como os argumentos que fundamentam as análises e a constituição dos enunciados, de modo que outros pesquisadores possam verificar as passagens e validar as interpretações expostas.

Em relação à interpretação e à compreensão das análises empreendidas, adotou-se a teoria hermenêutico-filosófica proposta por Gadamer (2014), cujo modelo teórico equipara, estruturalmente, a compreensão - no qual está inclusa a atividade interpretativa - ao conceito de jogo.

\section{RESULTADOS E DISCUSSÃO}

Nesta comédia, um dos protagonistas é William Judson, interpretado pelo ator Jean Hersholt. Ele é um corretor imobiliário, casado, bem-sucedido financeiramente, que atrai a atenção interesseira da personagem loira Marie Skinner, interpretada pela atriz Phyllis Haver. Vale destacar que o sobrenome desta personagem é foneticamente sugestivo - Skinner como "skinny", que, em inglês, significa algo como "magricela" ou "só pele e osso". Apesar dessas percepções, não se sabe se teria sido intenção dos roteiristas (Daniel Carson Goodman e Gerrit J. Lloyd) e/ou

3 Tese intitulada "História da obesidade no Cinema Mudo (1895-1927)", desenvolvida junto ao Programa de PósGraduação em Educação Física, da Universidade Federal de Pelotas (UFPel), defendida em julho de 2021. A amostra do trabalho foi composta por 806 filmes, divididos em séries, dentre as quais Hardy \& Laurel, Charles Chaplin, Buster Keaton, Georges Méliès, Roscoe Arbuckle, Max Linder e Harold Llloyd.

4 Conforme a Lei de direitos autorais, os filmes produzidos há 70 anos já se encontram em domínio público. 
do diretor Griffith. Apesar disso, dado o fato de que um dos temas centrais do filme é a corporeidade, e, considerando o que Bahiana (2012, s.p.) diz " [...] nada do que está na tela, em momento algum, é gratuito ou por acaso; tudo o que está na tela, a qualquer momento, tem uma razão de ser. Ou pelo menos deve ter - erros acontecem, acidentes também" - pode-se imaginar que foi proposital.

Também vale a pena destacar que a "citação de uma forma fílmica passa, necessariamente, pela referência a um corpo previamente construído, o do personagem fílmico" (GUIMARÃES, 2016, p.25) - ou seja, também o corpo do ator escolhido para atuar num determinado papel é constituído nesta representação. Como destacado por Guimarães (2016, p. 21), o "[...] corpo do ator no cinema pode transbordar sua utilidade meramente representacional para ser o local de referências estéticas, ideológicas e histórico-geográficas".

O perfil estereotipado do personagem homem rico de Judson já não é tão gordo quanto no começo do século, mas resta uma pequena barriga e um certo sobrepeso. Seduzido por Skinner, interessada em sua riqueza, ele começa a flertá-la e uma de suas primeiras atitudes para conquistar a moça consiste em tentar emagrecer. Numa das cenas, o personagem aparece em trajes de dormir, em seu quarto, lendo um livro, cujo título é "Poise and simmetry of figure: obesity, leanness - their causes and effects" - "Pose e simetria da figura: obesidade, magreza e suas causas". Esta obra realmente existe, tendo sido escrita por Susanna Crocoft e publicada em 1906.

O título e as atitudes do personagem, posteriormente, demonstram que a obesidade é problematizada enquanto estética corporal - e não como uma questão de saúde. Esse aspecto da problematização não relacionada à saúde no começo da inversão valorativa da corpulência e da gordura corporal excessiva foi encontrado e destacado em Santolin (2012) e também por Vigarello (2012). Como ressaltado, houve problematizações ético-morais desde a Antiguidade e durante o medieval, mas também houve uma inversão valorativa estética e, até mesmo, questões socioeconômicas e políticas que interferiram nas associações indiretas que passaram a ser realizadas com a condição, que, até então, era salutar, bela, rica, poderosa e desejável (SANTOLIN; RIGO, 2012; 2015; 2019).

Se até certo momento do filme o leve sobrepeso e a pequena circunferência abdominal deixavam alguma dúvida sobre a caracterização do personagem Judson, o subtítulo do livro que ele lê, seguido dos exercícios físicos que o personagem executa, esclarece, definitivamente, que o tema é, sim, a questão da obesidade do personagem. Não a obesidade definida como "gordura corporal excessiva" e diagnosticada com base no Índice de Massa Corporal (IMC), pela Organização Mundial da Saúde (OMS), mas a obesidade como "corpulento", "barrigudo" ou simplesmente "gordo". Ou seja, ainda que o termo "obesidade" apareça, este deve ser entendido no contexto do seu uso para não incorrermos em interpretações anacrônicas. Neste caso, o substantivo não possui uma precisão conceitual nem em relação ao tecido corporal - pois também se refere à antropometria, bastando ver o esforço do personagem para reduzir as medidas de sua circunferência abdominal nem em relação à quantificação de uma variável qualquer excessiva - pois o único instrumento de medição é a avaliação visual leiga mesmo. 
Aparentemente, o livro que o protagonista consultou é um manual, pois, junto à leitura, Judson põe-se a se exercitar (Figura 3). Fá-lo-á, entretanto, privadamente - quase secretamente - sozinho no quarto. O modo que executa os exercícios visou, aparentemente, soar cômico e ridículo. O personagem demonstra rapidamente exaustão, caindo ofegante deitado em decúbito dorsal sobre a cama.

Figura 3 - Fotograma 1

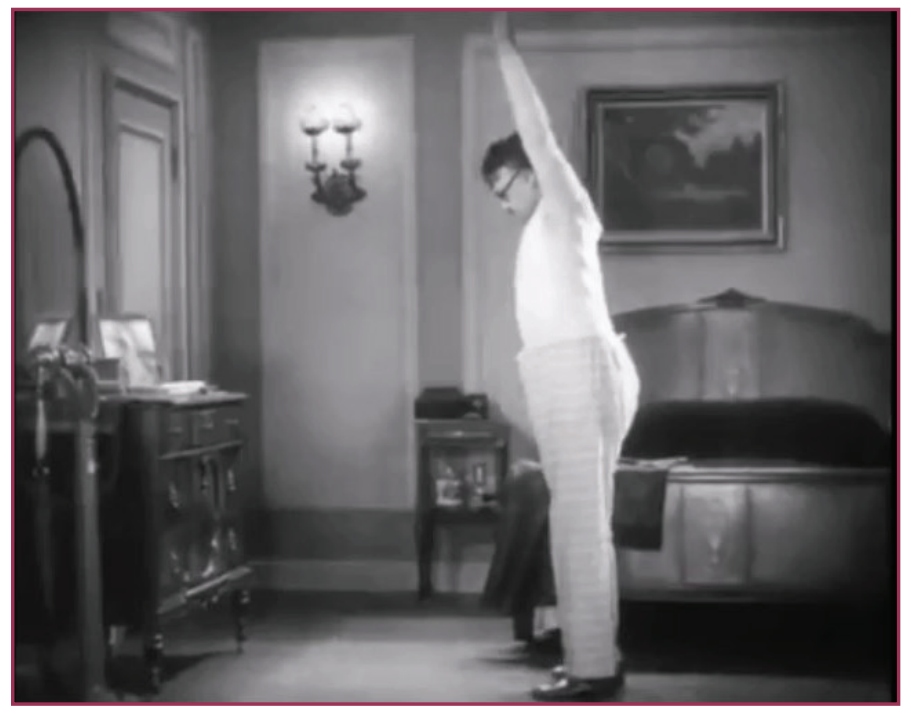

Fonte: A luta dos sexos, 1928

Numa nova sequência, aparece com um equipamento, com uma pequena esteira que é colocada na barriga (Figura 4), massageando-a, tal como era muito comum no começo do século XX. Acreditava-se que a massagem e a pressão sobre o abdome seriam suficientes para planificar a barriga. Judson usa o equipamento também nas costas, nas nádegas e no pescoço.

Figura 4 - Fotograma 2

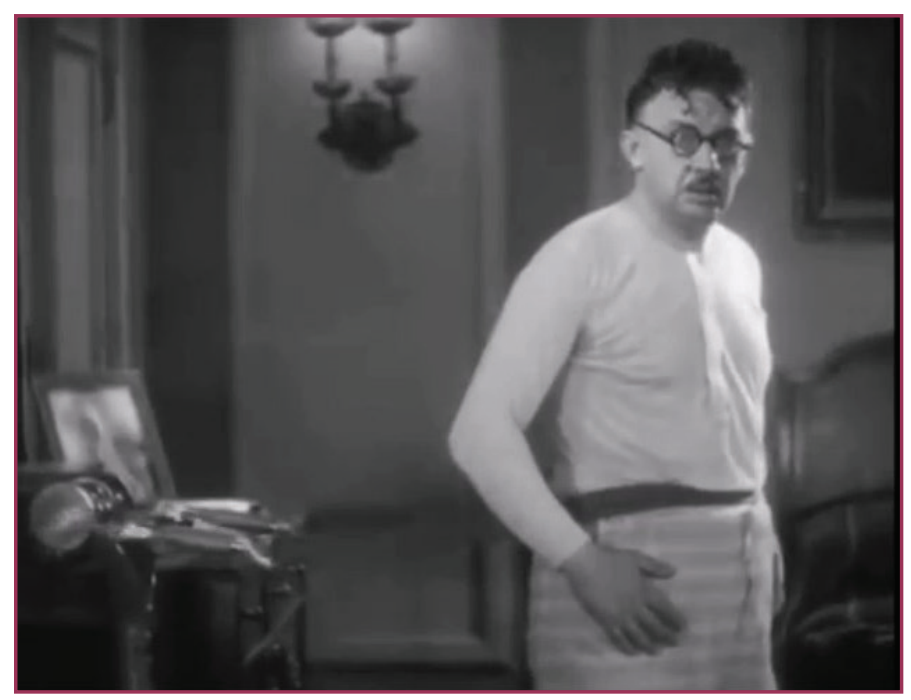

Fonte: A luta dos sexos, 1928

Em seguida a esse tratamento, demonstra conseguir fechar somente com dificuldade uma cinta na altura da barriga (Figura 5). Apesar de aparentar um esforço 
na manutenção da peça, expressa satisfação quando, posteriormente, aparece com o traje completo para ir visitar Skinner.

Figura 5 - Fotograma 3

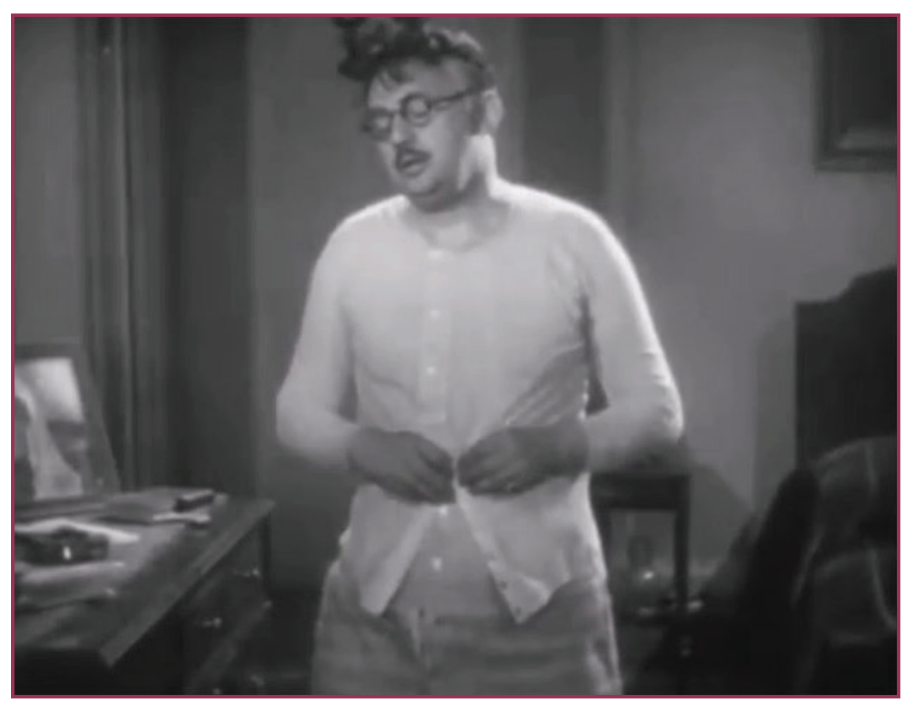

Fonte: A luta dos sexos, 1928

Um ponto central dessa tematização se relaciona ao sex appeal (apelo sexual) dos homens gordos. Se outrora, nos séculos passados, foram considerados atraentes, fogosos, mulherengos, potentes, viris etc., como pode ser visto em alguns filmes de Georges Méliès (MÉLIĖS , 2010) do final do século XIX, no século XX a representação que se fixará será a do homem gordo não atraente, cuja única possibilidade de sucesso junto às mulheres se reduz à condição do emagrecimento sine qua non tornam-se motivo de chacota ou de manipulação interesseira, como no filme de Griffith. Persiste a fogosidade sexual e amorosa, explicitada nas investidas sedutoras, mas agora resta o papel de enganado, daquele que tem seu apetite sexual manipulado, acreditando-se garanhão, mas sendo, na verdade, um "trouxa", ingênuo, que não percebe a real situação de seu flerte amoroso.

Aparentemente, essa formação discursiva já estava bem desenvolvida e difundida socialmente na França na época do lançamento do filme $A$ luta dos sexos (1928), inclusive na literatura. Henri Beraud, por exemplo, publica O martírio do obeso (1987), em 1922 - trama na qual um homem obeso é manipulado por uma mulher, que o usa para fazer ciúme no esposo, mas sem qualquer interesse real amoroso ou sexual no gordo, que, apaixonado, é enganado e motivo de ridicularização e piedade no final desta obra. E, no cinema mudo, o francês Max Linder lança Be my wife (1921) (LINDER, 2014), enunciando ideias semelhantes.

A outra formação discursiva - da baixa aptidão física - também já florescia, mas muito diminutamente, desde o começo do século no cinema, como, por exemplo, em O trovão de Júpiter (1903) (MÉLIĖS , 2010), de Georges Méliès, na França. Enunciações desse tipo aparecem novamente no filme quando Judson leva Skinner a um jantar e depois dançam. A princípio, ele se mostra apto, com boa destreza e habilidade na atividade, mas logo se cansa e apresenta um aspecto exausto, descabelado e suado, clamando a ela para que se sentem novamente. 
Por estar cansado demais para mais uma dança, cede a mão da moça para uma dança com um outro rapaz. Enquanto isso, o gordinho permanece à mesa, massageando os pés após tirar os sapatos. Ele boceja, apoiando a cabeça sobre a mão e, aparentemente, tirando um cochilo. Tem-se, portanto, enunciações que sugerem baixa aptidão física, principalmente cardiorrespiratória, de condicionamento aeróbio.

A esposa de Judson também estava no restaurante e vê o flerte infiel do marido. No dia seguinte, ambos acabam brigando, mas ele ainda prefere Skinner. Ao chegar à casa da moça, o outro homem que havia dançado com ela se encontrava lá e, após sair, Judson, enfurecido, briga com sua quase-amante por haver preterido sua família a alguém para quem nem mesmo ele era o único. Há uma formação discursiva com relativa recorrência - proveniente de ideias Antigas e Medievais (SANTOLIN, 2012, 2015) - que associam a corpulência excessiva à irascibilidade, agressividade e força física, e que ainda será recorrente no começo do século XX. Aqui, no caso, serão mantidas tais associações, porém serão desvalorizadas logo em seguida, tal como nos filmes de Buster Keaton. Apesar da fúria e da agressividade de Judson, a jovem tem um ataque histérico que sobrepõe a demonstração de irritação dele. Ele, ingenuamente, cede à manipulação. Ou seja, as associações relativamente positivas que eram realizadas anteriormente são valorativamente invertidas - a perspicácia do enganador vence a irascibilidade.

De volta à casa da família de Judson, a esposa chora enquanto lê a carta com o pedido de divórcio do marido. A filha do casal, Ruth, vê Skinner, junto a outra mulher, comentando "He's fat and dumb - but he gives me diamonds" - "Ele é gordo e estúpido - mas ele me dá diamantes". Nesta "fala" no intertítulo, a amante em potencial expressa explicitamente a desvalia estética pela corporeidade adiposa do protagonista. Até então não havia ficado claro que havia um real desprezo da moça nesse sentido, mas somente uma motivação financeiramente interessada.

A esposa de Judson se dirige ao topo do prédio, intencionando suicidar-se, mas é interrompida pela filha. Assim, a história vai ganhando contornos éticos e morais conservadores, do impacto que as jovenzinhas magras, sedutoras, imorais e irresponsáveis podem ter sobre as famílias ao seduzirem homens casados, pais de família.

A respeito da obesidade, indiretamente, enuncia-se, portanto, uma problematização da obsessão com a corporeidade, com a aparência corporal e com a magreza que surgia na época. Enquanto homem casado, pai de família, responsável - e "barrigudinho" - a esposa e a família não se importavam com isso e amavam-no verdadeiramente. Já a amante jovem sedutora fá-lo-á importar-se com tais futilidades, fazendo-o acreditar-se erroneamente amado. Há, enfim, subjacentemente, um elogio da irrelevância que uma "barriguinha" que um pai de família possa ter para sua esposa e para seus filhos, que o amariam pelo que ele é e não por dinheiro ou por estética. Assim, a jovem e magricela Skinner se torna a vilã da trama, juntamente com os novos valores - sobretudo, o de uma valorização da aparência corporal e da magreza.

Para salvar a mãe do suicídio e a família, a filha decide assassinar Skinner, mas não consegue executar o feito, restringindo-se à tentativa de convencimento da 
amante a deixar seu pai. Acaba sendo trancada num cômodo anexo, junto com o outro homem de Skinner, para escondê-los de Judson, que chega ao apartamento. O outro homem investe sedutoramente contra a filha de Judson, quando são intercedidos por Judson e Skinner, que adentram o quarto. Ruth, a filha de Judson, alega ser o namorado dele, gerando raiva tanto no pai quanto na amante.

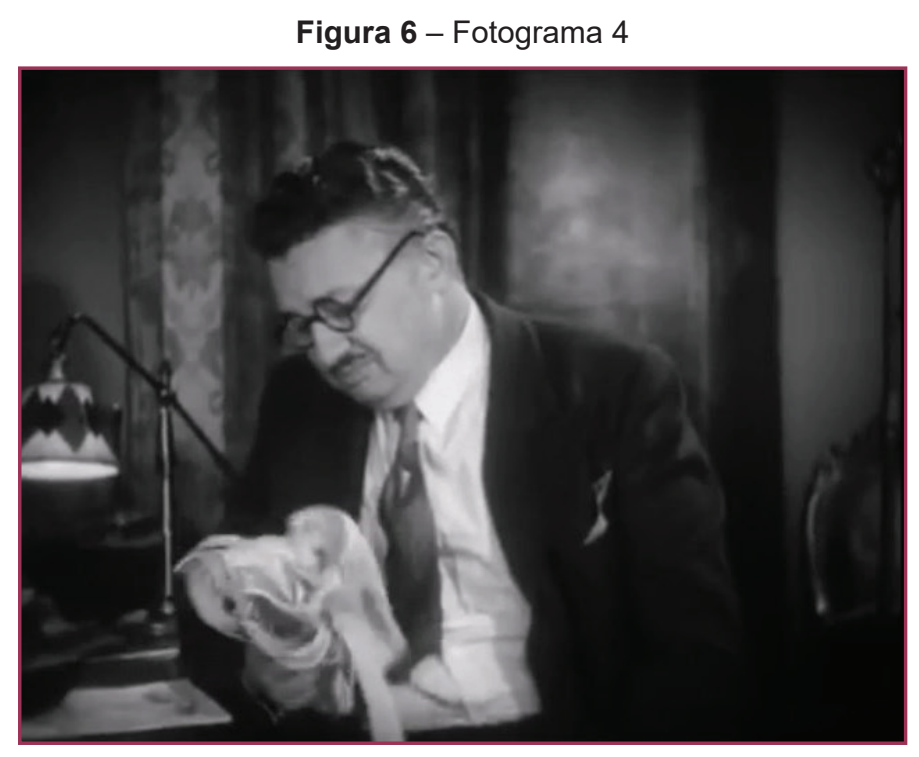

Fonte: A luta dos sexos, 1928

No fim, Judson rompe com Skinner e retorna para casa. No quarto, só, chorando, ele retira a cinta que prendia sua barriga, como um gesto de retorno à situação anterior à aventura adúltera (Figura 4). Arrependido, ele pede perdão à esposa e ambos se reconciliam. Assim, a filha se torna a heroína da história e a barriguinha um símbolo positivo de um pai de família fiel e de uma vida familiar íntegra, protegida das influências maléficas dos novos valores das novas gerações. Mensagem, enfim, conservadora dos antigos valores e, consequentemente, contrarrevolucionária no processo histórico de inversão valorativa relacionada à corpulência e gordura corporal excessivas que estava ocorrendo.

Considerando os pressupostos da teoria hermenêutico-filosófica de Gadamer (2014), que tornam o material empírico e as descrições analíticas da sessão anterior imprescindíveis, assume-se que a interpretação exposta é uma das possíveis, convidando outros autores a jogar o jogo hermenêutico.

Os resultados das análises permitem concluir que a obra em questão encerra em si peculiaridades enunciativas que a tornam uma formação discursiva rara na história da obesidade. Os conteúdos dos enunciados esboçam associações entre os novos valores para a época - o desejo de perder gordura corporal e, principalmente, de diminuir a circunferência abdominal - e comportamentos imorais, numa perspectiva conservadora, familiar e moralista.

Ao buscar explicitar esses enunciados expressos, tal como possibilita a análise discursiva da enunciação de Foucault (2008), constituindo-os como núcleos centrais dos argumentos nas mensagens veiculadas em tais representações sociais 
cinematográficas, conforme a teoria dos núcleos centrais, de Moscovici (2010) e Abric e Flament (PATRIOTA, 2020), tem-se:

1) O caráter é mais importante que a aparência corporal;

2) Desvios ético-morais subvertem esta hierarquia de valores;

3) A inversão valorativa acarreta perturbações na estrutura social, que levam a mudanças indesejáveis;

4) Logo, a conservação do status quo repousa sobre a manutenção daquela hierarquia de valores, na qual ser um bom pai e ser um bom marido, fiel, é mais importante do que ter uma aparência magra e uma forma esbelta.

De certo modo, pode-se dizer, portanto, que a formação discursiva em questão é contrarrevolucionária, no sentido de que contesta a inversão valorativa que estava em curso, associando-a a uma série de outros comportamentos retratados negativamente.

Essa contestação aos novos valores relacionados à obesidade e seus precursores conceituais também foi encontrada em outros meios, como num jornal inglês do século XIX, em Santolin (2012), no qual se critica a magreza de mulheres e se apresenta uma receita para engorda. Tais achados são relevantes por demonstrarem que uma inversão valorativa não ocorre sem contraposições, coincidindo com a máxima sugerida por Foucault (2009, p.105): “[...] onde há poder há resistência [...]".

Neste sentido, o filme analisado corrobora, também no cinema, o encontrado em outras pesquisas, refazendo, de certo modo, os caminhos discursivos realizados em jornais, livros e compêndios médicos. A diferença, entretanto, é que a ferramenta de comunicação em massa nesse caso é muito mais potente por alcançar maior público e usar linguagens fáceis, sobretudo no cinema mudo, podendo ter sido mais efetiva na divulgação dos novos valores.

Assim, pode-se constatar que a batalha discursiva se transferiu também para o território das representações audiovisuais, invadindo a nova mídia de massas. Mas deve-se destacar que a formação discursiva de resistência à inversão valorativa a que Griffith adere é quase inabitada. Do outro lado, com enunciados opostos, encontram-se importantes cineastas do cinema mudo, como Charles Chaplin, Buster Keaton, Harold Lloyd, Roscoe Arbuckle etc. Alguns, inclusive, usaram de retórica para vincular a corpulência excessiva à burguesia e a luta de classes, num viés comunista, como em A greve (1925), de Eisenstein.

Entretanto o plano de imanência de uma ou de outra dessa formação discursiva é o mesmo, no qual o corpo e sua aparência são progressivamente focados. Pois na sociedade moderna instituiu-se uma "anatomia política", uma "biopolítica", em que o corpo tornou-se alvo de relações de "biopoder" (FOUCAULT, 2008a, 2016). Nesse sentido, as condições de possibilidades discursivas deste plano delimitam as composições enunciativas, mas não dão conta de, por si só, explicar o que levou os discursos de inversão valorativa e de patologização da condição denominada obesidade prevalecerem.

Para investigar essa causalidade histórica complexa seria necessária uma análise externa à obra. Sem dúvida, há relações entre os filmes e seu contexto 
histórico de produção, mas como Ferro (1992, p.13) destaca, "Entre cinema e história, as interferências são múltiplas [...]”, e Vanoye e Goliot-Lètè (2002, p.56) complementam

Em um filme, qualquer que seja seu projeto (descrever, distrair, criticar, denunciar, militar), a sociedade não é propriamente mostrada, é encenada. Em outras palavras, o filme opera escolhas, organiza elementos entre si, decupa no real e no imaginário, constrói um mundo possível que mantém relações complexas com o mundo real: pode ser em parte seu reflexo, mas também pode ser sua recusa (ocultando aspectos importantes do mundo real, idealizando, amplificando certos defeitos, propondo um 'contramundo' etc.). Reflexo ou recusa, o filme constitui um ponto de vista sobre este ou aquele aspecto do mundo que lhe é contemporâneo.

Martelo ou espelho, como ressalta Ferro (1992, p.15), "Medir ou avaliar a ação exercida pelo cinema é difícil. Certos efeitos, pelo menos, são distinguíveis". Tarefa ainda mais delicada seria distinguir, primeiramente, se o que se representa são efeitos do contexto ou se são causas, sustentando isso com base em evidências documentais, já que, como este mesmo autor comenta, o cinema pode intervir também como agente da história, já que:

[...] desde que o cinema se tornou uma arte, seus pioneiros passaram a intervir na história com filmes, documentários ou de ficção, que, desde sua origem, sob a aparência de representação, doutrinam e glorificam. (FERRO, 1992, p.13)

Do mesmo modo, para explicitar certos processos socioculturais previstos na TRS, como a ancoragem e a objetivação, seria preciso ampliar o corpus empiricus fílmico e correlacionar estes materiais a acontecimentos exteriores do período, tal como a inserção da condição na Lista Internacional de Causas de Morte (LICM) (International List of Cause of Deaths - ILCD) - precursora da Classificação Internacional das Doenças (CID), no caso do processo histórico de patologização.

Neste artigo não se almejou dar conta dessas complexidades que as produções cinematográficas e suas representações estabelecem com o mundo real, com seu contexto, com seu período histórico, com a realidade sociocultural e econômica. Entende-se que a escrita desta trama é complexa e demandará múltiplas fontes, de diversos meios e proveniências.

\section{CONSIDERAÇÕES FINAIS}

Por fim, em vista do exposto, conclui-se que o filme-caso analisado se constitui como uma fonte primária importantíssima - dada sua raridade enunciativa e pela tematização direta - para a história da obesidade no cinema, havendo, entretanto, a necessidade de investigação de mais obras para compor um quadro histórico mais amplo, assim como análises externas às obras.

Para além disso, ao juntar-se a outras pesquisas, evidencia a tese de que o cinema foi uma ferramenta midiática de massa, que exerceu certo papel na história da obesidade. Ainda que a condição não tenha sido patologizada neste filme, entendese que a inversão valorativa foi um antecedente fundamental para que o discurso patologizante florescesse. 
Vale destacar que a formação discursiva da obra ainda é encontrada na atualidade - sejam as enunciações expressas verbalmente ou simplesmente praticadas. Se, naquela época, constituiu-se como contrarrevolucionária diante da inversão valorativa que se avolumava, atualmente, entretanto, os discursos que assumem a mesma posição se constituem como revolucionários, dado o fato de que o oposto prevaleceu.

Por fim, a título de sugestão a outros pesquisadores, cogita-se que obras cinematográficas posteriores à criação da Organização Mundial da Saúde (OMS), em 1948, possam conter uma formação discursiva patologizante.

\section{REFERÊNCIAS}

A LUTA DOS SEXOS. Direção de D. W. Griffith. Preto e branco, 88 min. Estados Unidos da América: Feature Productions e Art Cinema Corporation, 1928. Disponível em: https://www. youtube.com/watch?v=Mmi58GrzPjY\&ab_channel=CinematecadeAntig\%C3\%BCedades. Acesso em: 12 jan. 2022.

BAHIANA, Ana M. Como ver um filme. Rio de Janeiro: Nova Fronteira, 2012.

BARROS, João A. História serial, História quantitativa e História demográfica: uma breve reflexão crítica. Revista de Ciências Humanas, v. 11, n. 1, p. 163-172, jan. /jun. 2011.

BARROS, João A. A História serial e História quantitativa no movimento dos Annales. História Revista (Goiânia), v. 17, n. 1, p. 203-222, jan. /jun. 2012.

BARROS, João A. O projeto de pesquisa em História: da escola do tema ao quadro teórico. 9. ed. Rio de Janeiro: Vozes, 2013.

BERAUD, Henri. O martírio do obeso. Rio de Janeiro: Globo, 1987.

CHAPLIN, Charlie. Minha vida. 17. ed. Rio de Janeiro: José Olympio, 2015.

COUSINS, Mark. História do cinema: dos clássicos mudos ao cinema moderno. São Paulo: Martins Fontes, 2013.

FERRO, Marco. Cinema e História. Rio de Janeiro: Paz e Terra, 1992.

FOUCAULT, Michel. Os anormais: curso no Collège de France (1974-1975). São Paulo: Martins Fontes, 2001.

FOUCAULT, Michel. A arqueologia do saber. 7. ed. Rio de Janeiro: Forense Universitária, 2008.

FOUCAULT, Michel. História da sexualidade I: A vontade de saber. Rio de Janeiro: Graal, 2009.

FOUCAULT, Michel. Microfísica do Poder. 4. ed. Rio de Janeiro: Graal, 2016.

FOUCAULT, Michel. Nascimento da biopolítica: curso dado no Collège de France (19781979). São Paulo: Martins Fontes, 2008a. 
GADAMER, Hans-Georg. Verdade e método: traços fundamentais de uma hermenêutica filosófica. 15. ed. Rio de Janeiro: Vozes, 2014.

GOFFMAN, Erving. Estigma: notas sobre a manipulação da identidade deteriorada. Rio de Janeiro: Zahar, 1980.

GUIMARÃES, Pedro M. Corpo e citação. In: SAURA, Soraia C.; ZIMMERMANN, Ana C. (org.) Cinema e corpo. São Paulo: Laços, 2016. cap.1, p.21-32.

LINDER, Max. The Max Linder Collection. [New York]: Kino Lorber, 2014.

MÉLIĖS, Georges: the first wizard of Cinema (1896-1913). Direção de Georges Franju. Coleção. Lobster films. 6 DVDs. 896 min, França, 2010.

MOSCOVICl, Serge. Representações sociais. 7. ed. São Paulo: Vozes, 2010.

PATRIOTA, Lucia. M. Teoria das Representações Sociais: Contribuições para a apreensão da realidade. Disponível em: http://www.uel.br/revistas/ssrevista/c-v10n1 lucia.htm\#: :text=Quanto\%20\%C3\%A0s\%20fun\%C3\%A7\%C3\%B5es\%2C\%20as $\% 20$ representa\%C3\%A7\%C3\%B5es,et\%20son\%20public\%20(1961).\&text=(Abric\%2C\%20 1998\%3B\%20Moscovici\%2C,1978\%3B\%20Jodelet\%2C\%201986). Acesso em 18 de Setembro de 2020.

SABADIN, Celso. Vocês ainda não ouviram nada: a barulhenta história do cinema mudo. 2. ed. São Paulo: Lemos, 2000.

SANTOLIN, Cezar B. O nascimento da obesidade: um estudo genealógico do discurso patologizante. Dissertação (Mestrado em Educação Física) - Escola Superior de Educação Física, Universidade Federal de Pelotas, Pelotas, RS, 2012.

SANTOLIN, Cezar B.; RIGO, Luiz C. O nascimento do discurso patologizante da obesidade. Movimento (Porto Alegre), v. 21, n. 1, p. 81-94, jan./mar. 2015. DOI: https://doi. org/10.22456/1982-8918.46172.

SANTOLIN, Cezar B.; RIGO, Luiz C. A obesidade e a problematização da corpulência na Idade Média. FIEP BULLETIN ON-LINE, v. 82, Spec. Ed. , 2012. Disponível em: http://www. fiepbulletin.net/index.php/fiepbulletin/article/view/2305. Acesso em: 11 jan. 2022.

SANTOLIN, Cezar B.; RIGO, Luiz C. Por que o termo "gordo" se tornou politicamente incorreto no Brasil? In: CONGRESSO SULBRASILEIRO DE CIÊNCIAS, 6 DO ESPORTE, 6. 2012a. Anais. Disponível em: http://congressos.cbce.org.br/index.php/6csbce/sul2012/ paper/view/3978 Acesso em: 25 jan. 2022.

SANTOLIN, Cezar B.; RIGO, Luiz C. Representações da obesidade no cinema: o "burguês gordo" em A greve (1925) de Eisenstein. Movimento (Porto Alegre), v. 25, e25076, 2019. DOI: https://doi.org/10.22456/1982-8918.91815.

STRUNA, Nancy L. Pesquisa histórica em atividade física. In: THOMAS, Jerry R.; NELSON, Jack K.; SILVERMAN, Stephen J. Métodos de pesquisa em atividade física. 5. ed. Porto Alegre: Artmed, 2007. cap. 12, p. 189-201.

THOMAS, Jerry R.; NELSON, Jack K.; SILVERMAN, Stephen J. Métodos de pesquisa em atividade física. 5. ed. Porto Alegre: Artmed, 2007.

VANOYE, Francis; GOLIOT-LÉTÉ, Anne. Ensaio sobre a análise fílmica. 2. ed. São Paulo: Papirus, 2002.

VIGARELLO, Georges. As metamorfoses do gordo. Rio de Janeiro: Vozes, 2012. 
WORLDWIDEBOXOFFICE. Disponível em: < http://www.worldwideboxoffice.com/> Acesso em: 11 jan. 2022.

YIN, Robert K. Estudo de caso: planejamento e método. 5. ed. Porto Alegre: Bookman, 2015. 
Abstract: The aim of this article was to analyze The battle of the sexes (1928), by D. W. Griffith, as a primary source of the history of obesity in cinema. Methodologically, discoursive analysis of enunciation was used in a Foucaultian perspective. The analysis showed the importance that the issue of obesity and abdominal circumference assume in the plot. Both are made symbolic and the new values, portrayed negatively, as an indirect, threat to the integrity of families. Consequently, the belly and the little importance given by the wife and the children due to the true love they feel for the husband / father become symbols of good parenthood, fidelity and family integrity. It is concluded that the film is an important piece in the history of obesity both because Griffith was one of the most important filmmakers in the history of cinema and this one of his most famous films and because of the rarity of the discursive formation.

Keywords: Obesity. History. Motion pictures.

Resumen: El objetivo de este artículo fue analizar la película La lucha de los sexos (1928), de D. W. Griffith, como una fuente primaria de la historia de la obesidad en el cine. Metodológicamente, se utilizó análisis discursiva de la enunciación en una perspectiva foucaultiana. Los análisis permitieron constatar la importancia que el tema de la obesidad y de la circunferencia abdominal asumen en la trama. Ambas se vuelven simbólicas y los nuevos valores son retratados negativamente como una amenaza, indirecta, a la integridad de las familias. En consecuencia, la barriguita y la poca importancia dada a esta por la esposa y los hijos debido al amor verdadero que sienten por el marido/padre se convierten en símbolos de buena paternidad, de fidelidad y de integridad familiar. Se concluyó que la película es una pieza importante en la historia de la obesidad tanto porque Griffith fue uno de los cineastas más importantes de la historia del cine y esa es una de sus películas más famosas, como por la particularidad de la formación discursiva.

Palabras clave: Obesidad. Historia. Películas cinematográficas. 


\section{(10 MOVIMENTO

NOTAS

\section{LICENÇA DE USO}

Este é um artigo publicado em acesso aberto (Open Access) sob a licença Creative Commons Atribuição 4.0 Internacional (CC BY 4.0), que permite uso, distribuição e reprodução em qualquer meio, desde que o trabalho original seja corretamente citado. Mais informações em: https://creativecommons.org/licenses/by/4.0

\section{CONFLITO DE INTERESSES}

Os autores declararam que não existe nenhum conflito de interesses neste trabalho.

\section{CONTRIBUIÇÕES AUTORAIS}

Cezar Barbosa Santolin: Idealização, metodologia, investigação, descrição, análise, escrita.

Luiz Carlos Rigo: Escrita - revisão e edição, supervisão..

\section{FINANCIAMENTO}

O presente trabalho foi realizado sem o apoio de fontes financiadoras.

\section{COMO REFERENCIAR}

SANTOLIN, Cezar Barbosa; RIGO, Luiz Carlos. História da obesidade no cinema: a luta dos sexos (1928) de D. W. Griffith. Movimento, v.28, p. e28006, jan./dez. 2022. DOI: https://doi.org/10.22456/1982-8918.114205. Disponível em: https://seer. ufrgs.br/Movimento/article/view/114205. Acesso em: [dia] [mês abreviado]. [ano].

\section{RESPONSABILIDADE EDITORIAL}

Alex Branco Fraga*, Elisandro Schultz Wittizorecki*, Ivone Job*, Mauro Myskiw*, Raquel da Silveira*

*Universidade Federal do Rio Grande do Sul, Escola de Educação Física, Fisioterapia e Dança, Porto Alegre, RS, Brasil. 